\title{
СИСТЕМА СТАБІЛІЗАЦІЇ ПОТУЖНОСТІ РІЗАННЯ МЕТАЛООБРОБНОГО ВЕРСТАТА
}

\author{
Водічев В.А. ${ }^{1}$, Монтік П.М. ${ }^{2}$, Алдаїрі Алі ${ }^{1}$ \\ ${ }^{1}$ Одеський національний політехнічний університет, Одеса \\ ${ }^{2}$ Одеська національна академія харчових технологій, Одеса
}

Copyright (C) 2014 by author and the journal "Automation technological and business - processes". This work is licensed under the Creative Commons Attribution International License (CC BY). http://creativecommons.org/licenses/by/4.0/

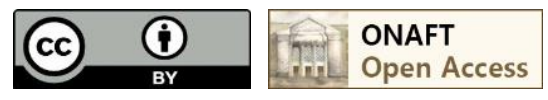

DOI: $10.15673 / 2312-3125$.

\section{Анотація}

Робота присвячена удосконаленню системи стабілізації потужності різання легкого фрезерного верстата. Актуальність розробки обумовлена тим, що відомі регулятори, які забезпечують високу точність підтримки заданого рівня потужності в усталених режимах і добру якість перехідних процесів, мають складну технічну реалізацію з застосуванням нейронних мереж і фазі - контролерів. Їх використання суттєво збільшує ціну верстата. Регулятори, що мають просту технічну реалізацію і низьку ціну, підтримують потужність різання в усталених режимах зі значною похибкою і не забезпечують стійкість системи стабілізації в умовах зміни в широких межах глибини i ширини різання, твердості оброблюваної заготівки і стану інструменту. Запропонована в статті структура системи стабілізації потужності різання при простій технічній реалізації розв'язує вказане протиріччя. В системі використано два кола регулювання. Перше коло містить від'ємний зворотний зв'язок за потужністю різання і нелінійну ланку 3 насиченням, яка забезпечус обмеження максимальної швидкості подачі стола верстата. Друге коло регулювання містить інтегральний регулятор, який в умовах зміни збурюючих впливів на процес обробки забезпечус зміну сигналу задання потужності різання на вході внутрішнього кола регулювання. Така побудова системи надає їй властивостей астатизму за збуренням. Дослідження роботи системи проведене на моделі для випадку фрезерування стальної заготівки в умовах зміни глибини різання щаблями. Результати моделювання свідчать, що запропонована система забезпечус добру якість перехідних процесів в умовах зміни коефіціснта передачі процесу обробки, а в усталених режимах потужність різання підтримусться на заданому рівні без похибки.

\section{Abstract}

The paper is devoted the improvement of the system of stabilizing of cutting power of light milling machine. The working out urgency is caused by that known regulators which ensure high accuracy of maintenance of the set power level in steady states and high quality of transients, have complicate technical implementation with application of neural webs and fuzzy - control units. Their use essentially augments the machine tool price. Regulators which have simple technical implementation and the low price, maintain power of cutting in steady states with a considerable error and do not ensure stability of system of stabilization in the conditions of change over a wide range depth and width of cutting, hardness of a work piece and an instrument condition. The structure of system of stabilization of power of cutting offered in paper at simple technical implementation solves the specified contradiction. In system it is used two closed loops of regulating. The first closed loop contains negative feedback on power of cutting and a nonlinear link with saturation which ensures limitation of the maximum feed rate of a table of the machine tool. The second closed loop of regulating contains an integral regulator which in the conditions of change of the gain of machining process ensures change of a signal of the demanded power of cutting on an entry of an internal closed loop of regulating. Research of operation of system is carried out on model for a case of milling of steel preform in the conditions of change of a cutting depth by steps. Results of simulation testify that the offered system ensures high quality of transients in the conditions of change of a transfer ratio of process of machining, 


\section{$\underline{2}$ АВТОМАТИЧНІ ТА АВТОМАТИЗОВАНІ СИСТЕМИ УПРАВЛІННЯ ТЕХНОЛОГІЧНИМИ ПРОЦЕСАМИ}

and in steady states power of cutting is maintained at the set level without an error.

Ключові слова

Система, регулятор, зворотний зв'язок, перехідний процес.

Для підвищення продуктивності обробки на металообробних верстатах застосовуються автоматизовані системи стабілізації потужності різання, що керують швидкостями електроприводів подачі [1]. Оскільки у системах стабілізації потужності в умовах зміни глибини і ширини обробки, стану інструменту, твердості оброблюваної заготівки відбувається зміна в широких межах коефіцієнта підсилення ланки системи, що представляє об'єкт керування, то для забезпечення стійкості систем і потрібної якості перехідних процесів застосовуються достатньо складні за технічною реалізацією адаптивні, нейронні і нечіткі регулятори $[1,2,3]$. У сучасних ринкових умовах на підприємствах часто використовуються металообробні верстати з невисоким рівнем автоматизації і відповідно невисокою ціною, яку не доцільно збільшувати за рахунок застосування складних регуляторів. Для цих верстатів актуальною є розробка достатньо простого і не коштовного регулятора для стабілізації потужності обробки, що забезпечить підвищення продуктивності верстата при задовільних статичних і динамічних характеристиках системи керування.

Метою статті удосконалення автоматизованої системи стабілізації потужності різання металообробного верстата шляхом спрощення технічної реалізації регулятора зі збереженням високої точності регулювання в усталених режимах і доброї якості перехідних процесів в умовах зміни коефіцієнта передачі об'єкта керування.

До складу автоматизованої системи стабілізації потужності різання легкого фрезерного верстата (рис. 1) входять

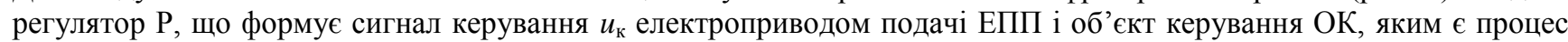
обробки, двигун головного руху верстата і датчик його активної потужності ДД, що формує сигнал зворотного зв'язку $u_{\Pi}$. ЕПП виконано за системою перетворювач - двигун П - Д постійного струму 3 передаточним

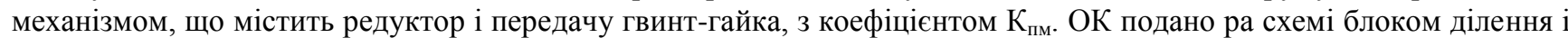
нелінійною ланкою, що відтворюють залежність потужності обробки від швидкості подачі $S$, частоти обертання $n$, кількості зубів $z$ фрези і глибини обробки $t_{p}$ відповідно до емпіричних формул [4]. Динамічні ланки в складі ОК і ДД враховують передаточні функції процесу обробки, асинхронного двигуна головного руху і датчика його активної потужності зі сталими часу $\mathrm{T}_{\text {пп }}, \mathrm{T}_{\text {д }}, \mathrm{T}_{\text {дп }}$ відповідно.

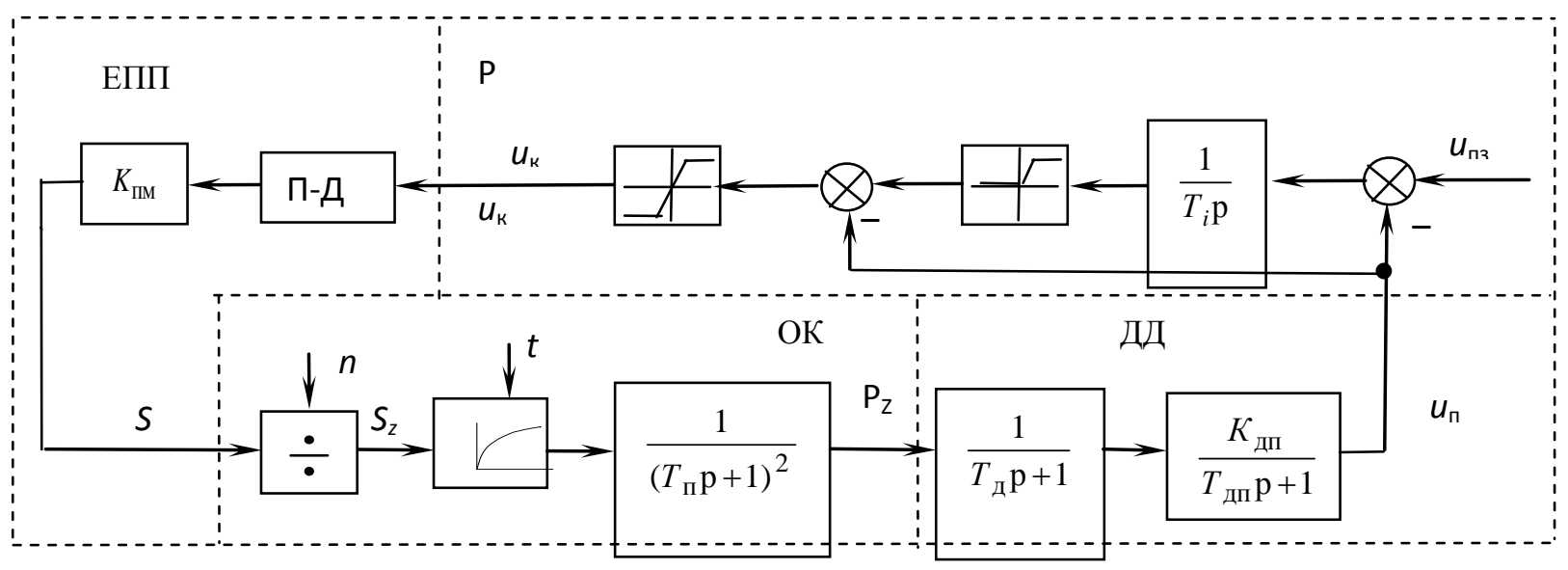

Рис. 1. Структурна схема системи стабілізації потужності різання

Відомий регулятор (рис. 2) містить ланцюг зворотного зв’язку за потужністю обробки [1], у якому сигнал $u_{\text {пз }}$ визначає задане значення потужності, а сигнал $u_{\text {шз }}$ - максимальне значення швидкості подачі при поточному значенні потужності, меншому за задане. При застосуванні такого регулятора статична характеристика лінеаризованої замкнутої системи описується рівнянням 


\section{2 АВТОМАТИЧНІ ТА АВТОМАТИЗОВАНІ СИСТЕМИ УПРАВЛІННЯ ТЕХНОЛОГІЧНИМИ ПРОЦЕСАМИ}

$$
P_{z}=\frac{\left(u_{\text {шз }}+u_{\Pi 3} K_{\mathrm{p}}\right) K_{\mathrm{e \Pi}} K_{\Pi}}{1+K_{\text {дп }} K_{\mathrm{p}} K_{\text {еп }} K_{\Pi}}
$$

де $K_{\text {еп, }}, K_{\text {п }}, K_{\mathrm{p}}$ - коефіцієнти передачі електропривода подачі, процесу обробки і регулятора потужності відповідно.

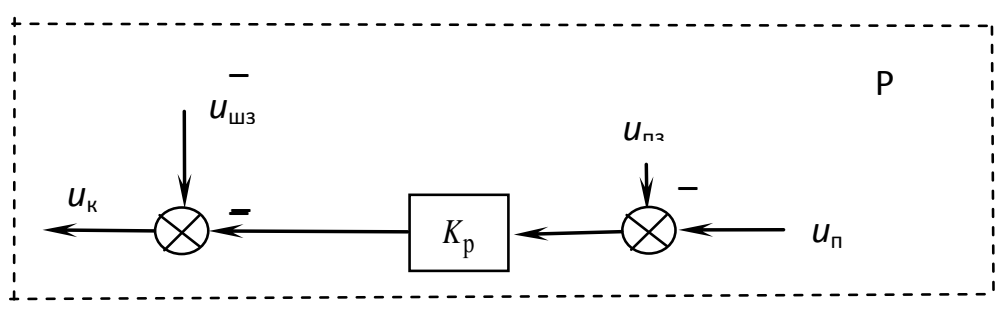

Рис. 2. Структурна схема відомого регулятора потужності різання

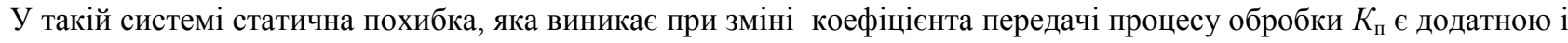
зменшується зі збільшенням коефіцієнта підсилення регулятора $K_{\mathrm{p}}$. Забезпечення високої точності стабілізації потужності обробки потребує суттєвого збільшення коефіцієнта $K_{\mathrm{p}}$, що призводить до погіршення якості перехідних процесів і при певних змінах припуску, що знімається, і стану інструменту, система втрачає стійкість. Застосування достатньо складних корегувальних пристроїв забезпечує стійкість системи, проте, вона залишається статичною. Суть удосконалення системи, що пропонується, полягає у відмові від застосування корегувальних пристроїв у статичній системі і створенні внутрішнього кола регулювання з одиничним коефіцієнтом підсилення регулятора потужності $K_{\mathrm{p}}=1$, за якого система $\epsilon$ стійкою при всіх можливих змінах коефіцієнта $K_{\text {п }}$. Для забезпечення в цих умовах високої точності стабілізації потужності різання до складу системи (рис. 1) введено зовнішне коло регулювання, яке містить ланцюг з інтегруючою ланкою зі сталою часу $T_{\mathrm{i}}$ i суматором, який при зміні основного сигналу зворотного зв'язку за потужністю обробки забезпечує зміну значення сигналу, що визначає задану потужність різання для внутрішнього кола регулювання. У внутрішньому колі застосовано нелінійну ланку з насиченням, яка забезпечує обмеження максимальної швидкості подачі стола верстата при значенні потужності різання, що $є$ меншою за задане.

Дослідження роботи розглянутої автоматизованої системи стабілізації потужності різання для легкого фрезерного верстата 6Б75В виконано на моделі, що складена в середовищі Simulink, відповідно структурній схемі (рис.1). Модель електропривода подачі верстата відповідає комплектному електроприводу постійного струму типу ЕШІМ1. Розглянуто керування процесом фрезерування кінцевою фрезою з швидкоріжучої сталі заготівки зі сталі, що має три щаблі з різною глибиною різання. Задане значення потужності обробки складає 1,5 кВт. Результати моделювання подані у вигляді графіків залежностей потужності різання $P_{z}$, швидкості подачі $S$, глибини різання $t_{p}$ від часу $t$ (рис. 3). 3 графіків видно, що при врізанні інструменту в заготівку перерегулювання потужності різання не перевищує 15\% від усталеного значення, а в умовах зміни припуску, що знімається, - 20 \%. В усталеному режимі потужність підтримується на заданому рівні без похибки.

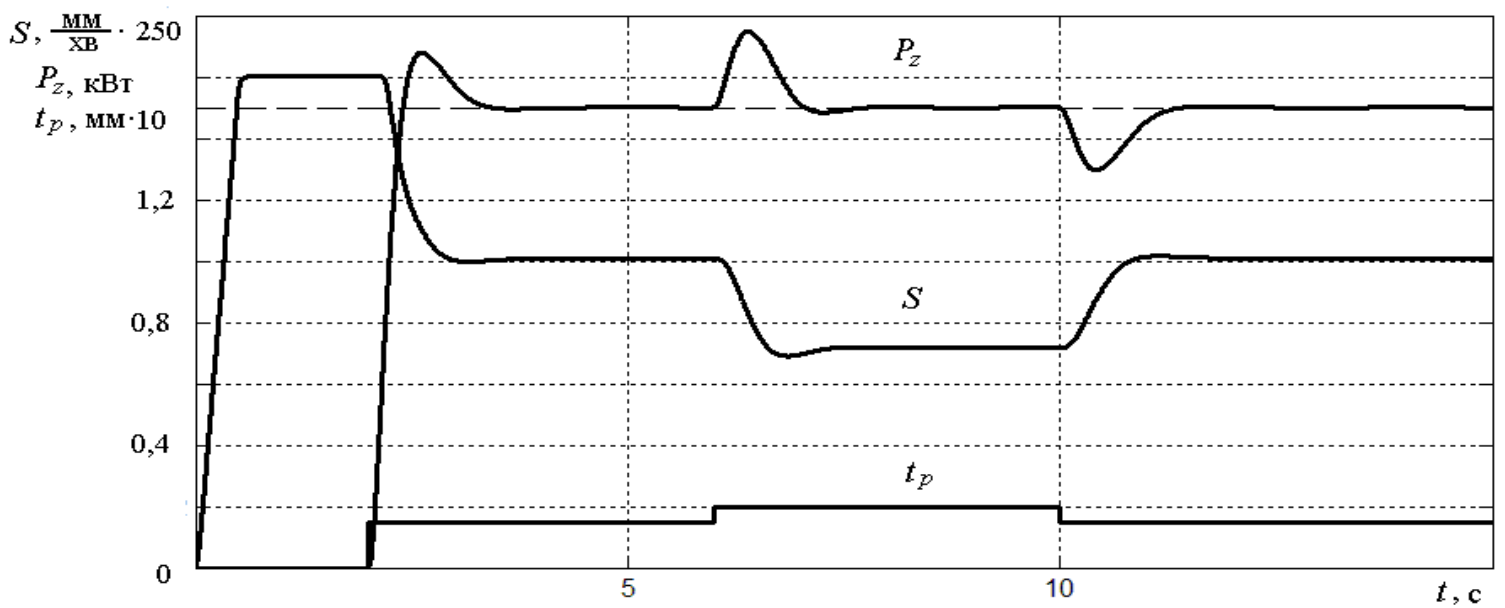

Рис. 2. Графіки процесів у системі стабілізації потужності обробки 


\title{
$\underline{2}$ АВТОМАТИЧНІ ТА АВТОМАТИЗОВАНІ СИСТЕМИ УПРАВЛІННЯ ТЕХНОЛОГІЧНИМИ ПРОЦЕСАМИ
}

Проведене дослідження показало, що застосування запропонованого регулятора в системі стабілізації потужності різання фрезерного верстата забезпечує прийнятну якість перехідних процесів, що виникають при зміні збурень, і стабілізацію потужності в усталених режимах на заданому рівні без похибки. Стандартні ланки, що входять до структурної схеми рис. 1, можуть бути реалізовані на операційних підсилювачах. Простота технічної реалізації обумовлює низьку вартість регуляторів, їх застосування на легких фрезерних верстатах забезпечуватиме підвищення продуктивності верстатів на 10 - 20 \% і не потребуватиме значних капіталовкладень.

\section{References}

1. Shaparev N.K. Raschet avtomatyzyrovannykh elektropryvodov system upravlenyya metalloobrabotkoy. - K.: Lybyd', 1992. - 272 s.;

2. Zakutnyy A.S. Metodyka synteza neyrosetevoy systemy stabylyzatsyy moshchnosty rezanyya // Elektromashynobuduvannya ta elektroobladnannya: Mizhvid. nauk.-tekhn. zbirnyk. - K.: Tekhnika. - 2001. Vyp. 56. - S. 10-15;

3. Vodychev V.A., Hulyy M.V., Mukhammed M.A. Prymenenye fazzy-rehulyatora v elektromekhanycheskoy systeme avtomatyzatsyy metalloobrabotky // Visnyk Natsional'noho tekhnichnoho universytetu „Kharkivs'kyy politekhnichnyy instytut”. - Kharkiv: NTU „KhPI”, 2005. - \# 45. - S. 504 - 505.;

4. Spravochnyk tekhnoloha - mashynostroytelya. V 2-kh t. T.2/ Pod red. A.H. Kosylovoy, R.K. Meshcheryakova. M.: Mashynostroenye, 1986. - 496 s.

\section{АКСИАЛЬНЫЙ ОФСЕТ КАК МЕРА УСТОЙЧИВОСТИ ЛЕГКОВОДНОГО ЯДЕРНОГО РЕАКТОРА ПРИ СУТОЧНОМ МАНЕВРЕ МОЩНОСТЬЮ.}

\author{
Никольский М.В. ${ }^{1}$ \\ ${ }^{1}$ Одесский национальный политехнический университет, Одесса
}

Copyright (C) 2014 by author and the journal “Automation technological and business - processes”. This work is licensed under the Creative Commons Attribution International License (CC BY). http://creativecommons.org/licenses/by/4.0/

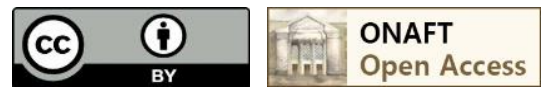

DOI: $10.15673 / 2312-3125$.

\begin{abstract}
Аннотация
Требованиями, предъявляемыми при эксплуатации энергоблока в маневренном режиме, являются высокая надежность и безопасность энергоблока, которые зависят от устойчивости реактора при переходе с одного уровня мощности на другой. Количественной мерой устойчивости реактора является аксиальный офсет. Двузонная модель реактора позволила контролировать изменение нейтронно-физических и технологических параметров по высоте ВВЭР-1000. Идентифицирована модель борного регулирования, которая отличается от известных тем, что ввод борной кислоты в теплоноситель вводится монотонно.

Показано, что изменение температуры на входе в активную зону реактора наносит неконтролируемое возмущение, которое влияет на аксиальный офсет и, как следствие, на устойчивость реактора. Для обеспечения устойчивости реактора предложен компромисно-комбинированный метод регулирования, который отличается от известных тем, что температура теплоносителя на входе в АКЗ реактора поддерживается постоянной за счет изменения давления пара в парогенераторе вследствие изменения положения регулирующих клапанов турбины.
\end{abstract}

